Y ou will notice several changes in our appearance in this issue. Firstly, the cover page has changed to note that our primary audience is primary care and internal medicine.

Secondly, to break up the text and make the texts more visually appealing and readable, we are adding different fonts, different shading, and icons. You might have noted the "100 faces" Figure (courtesy of Dr Chris Cates's Visual Rx: www.nntonline.net) in the September/October issue last year. We plan to continue and extend such visual representations. Thirdly, in this issue you'll note a number of changes to the abstract. The study question is led by a blue " $\mathrm{Q}$ ". The Methods have changed from full sentences to an icon and point form. For example, the drawing for the design represents a randomised trial, but the same icon will be used for all designs and will not be redrawn for a cohort study. Similarly, the patient icon is a person in a hospital bed. We hope that the result is more visually stimulating and appealing, and will increase your reading speed and understanding of the content!

Finally, to provide a more varied reading diet, we have also changed the mix of content. A few of the previous abstracts have been replaced by more general material, including a regular practice corner and a general editorial that will highlight particular features or issues relevant to the journal or to EBM more generally. This issue, we'd like to let you know a little more about the enhanced features of the online version. Happy reading/browsing!

\title{
The Centre for Evidence-Based Medicine 9th UK workshop
}

T he 2003 workshop was held at a new venue: Oriel College-part of Oxford University, in the centre of Oxford City, adjacent to the High Street, and one of the oldest colleges in Oxford (its former graduates include Sir Walter Raleigh and Cecil Rhodes). With its beautiful old buildings situated around quadrangles, participants could imagine what it would be like to be an undergraduate here.

The workshop was chaired by Professor Paul Glasziou, soon to start his new position as Director of Centre for Evidence-Based Medicine in Oxford. The format was the tried and tested one of a morning lecture followed by twice daily small group workshops (the small groups remained together the whole week), plus daily after-lunch participant ad-hoc discussion groups (PADs). PAD sessions allowed those with similar interests or needs to meet outside their usual groups. Organised by both tutors and participants, they were highly popular sessions, with subjects including running journal clubs, evidence-based medicine (EBM) in real time, and EBM curriculum development. Each group had 2 facilitators, who were various healthcare professionals with an extensive knowledge and experience of EBM. Although activities "finished" at 6 pm, many groups burned the midnight candle, though other participants could be seen congregating at the porters lodge and sloping off to one of the many and varied local public houses.

Participants had a variety of disciplinary backgrounds (eg, epidemiologists, librarians, occupational therapists, and physicians assistants) and came from various parts of the world, including Hong Kong, Japan, USA, Taiwan, Mexico, Canada, and even Scotland. There was wide and varied knowledge on offer from all different aspects of health care.

When attending such a course, it is relevant to ask, "What exactly am I going to get out of it?" Definitely beautiful and nostalgic surroundings; the chance to meet people with similar problems and enthusiasms; the chance to get to grips with the many areas of critical appraisal and methods for finding evidence and using it in your practice; help in curriculum development; and the opportunity to network with people with similar needs and problems. It is beneficial to attend such courses a number of times: as with technology or your latest laptop, it and you can get out of date pretty quickly.

Albert Einstein once observed, "The significant problems we face cannot be solved at the same level of thinking we were at when we created them." If the pace of EBM development is as fast as it has been in the last decade, then I look forward to the coming years.

Details of future workshops can be found by going to the Centre for Evidence-Based Medicine's website www.cebm. net and clicking "events."

CARL HENEGHAN, BM, BCH, BA Centre for Evidence-Based Medicine Oxford, UK 